\title{
AGROECOLOGIA: AS CLASSES EM SEU LUGAR?
}

Paulo Freire Mello ${ }^{1}$

Agroecologia: as coisas em seu lugar (a Agronomia brasileira visita a terra dos duendes), de Navarro (2013), é um texto indispensável para aqueles que lidam com a temática. Em linhas gerais, temos concordância com seu argumento. Assim, procuraremos complementá-lo com breves comentários gerais e com algumas proposições de pesquisa, visando iluminar pontos que, em nossa opinião, ainda estão pouco esclarecidos.

Na década de 1980, o termo "agricultura alternativa" abrigava uma série de correntes, surgidas em diversos lugares, que tinham em comum a proposição de técnicas agronômicas menos agressivas ao meio ambiente e menos dependentes de insumos externos. Naquele período, e com relação à discussão brasileira, as obras de referência geralmente tratavam de técnicas agronômicas, mas, em muitos casos, já havia um ideário anticapitalista. Um de seus desdobramentos era o combate à grande agroindústria, quer dizer, "o Capital e suas tramas diabólicas": controle das sementes, dos insumos, dos mercados, dos agricultores. De outro lado, seguindo a esteira de "não sabemos o que queremos, mas sabemos o que não queremos", criticava-se a "agricultura moderna", hoje chamada de "agronegócio", por ser considerada destruidora do ambiente e das economias familiares.

Décadas se passaram, e a expressão transitou de "alternativa" para "ecológica", talvez indicando um arrefecimento da luta ideológica, mas acabou se consolidando na ideia de "agroecologia", desta vez, como bem descreve Navarro, com uma ambição aparentemente científica. $\mathrm{O}$ autor demonstra a fragilidade teórica que circunda a expressão ${ }^{2}$ e os resultados pífios de suas proposições entre os agricultores.

Quanto a essa última questão, cita-se uma razão adicional às do texto sob análise: mesmo que não exista um modelo alternativo acabado, como bem alerta Navarro, ainda assim, conta-se com técnicas agrícolas já amplamente utilizadas dentre os ecologistas. Ocorre que essas técnicas, via de regra, geram baixas produtividades e alto risco. Como se sabe, a aversão ao risco - sem querer ressuscitar o debate sobre o "campesinato",

\footnotetext{
${ }^{1}$ Engenheiro Agrônomo do INCRA, Doutor em Desenvolvimento Rural. pfreiremello@yahoo.com.br 2 Ainda que se considere o citado primitivismo teórico da agroecologia, guardadas as devidas proporções, somos tentados a uma analogia com a Ontologia Política de Martin Heidegger, quando Bourdieu (1989) discute como, fruto das imposições do campo e do habitus, pode uma estratégia de retórica política (no caso, nazista) ser sublimada na forma filosófica.
} 
como parte da literatura brasileira que trata do rural faz - é uma antiga característica camponesa (MENDRAS, 1978) ainda marcante para grande parcela dos agricultores familiares, especialmente para aqueles (não poucos) desprovidos.

No que tange aos diferenciais de produtividade, embora com a limitação que advém da falta de estudos comparativos amplos, a situação poderia ser colocada nos seguintes termos: à exceção dos pequenos grupos que ocupam nichos específicos voltados à parcela mais rica da população e que se dispõem a pagar algo entre 50 e 100\% a mais do que os produtos "convencionais", como sustentar um mundo de sete bilhões de pessoas com tecnologias que reduzem drasticamente a produção? Dobrando a área plantada? Será viável?

Desnecessário dizer que ainda não se dispõe de um cabedal de técnicas agronômicas eficazes e seguras que nos permitam dispensar o uso de adubos solúveis e agrotóxicos. Quando se fala em segura, consideram-se, pelo menos, duas dimensões: a segurança econômica, que, para uma multidão, significa segurança de vida mesmo, basta considerar o caso dos agricultores paupérrimos do sertão nordestino; e a segurança sanitária. É bem conhecido o extremo rigor com o qual, na Europa, controlam-se os alimentos produzidos "organicamente", haja vista o risco de contaminação biológica.

Outro limitante da chamada agroecologia, apresentado por Navarro, diz respeito à (verdadeira) dificuldade de se obter mão-de-obra no campo. Talvez seja o caso de contextualizarmos brevemente. $\mathrm{O}$ Brasil tem mais de cinco milhões de estabelecimentos rurais (compare-se com os EUA, que têm dois milhões e produz muito mais do que o Brasil), $8 \%$ dos quais produz $85 \%$ de toda a produção agropecuária, medida pelo Valor Bruto da Produção; enquanto que $73 \%$ do total de estabelecimentos produzem menos de $4 \%$ do total (ALVES; ROCHA, 2010). Tal quadro assombroso de concentração da produção, mais relevante do que a própria concentração fundiária, é o resultado de algumas décadas de desenvolvimento da agropecuária brasileira. Engendrou-se, por conta da alta competitividade que aí se instalou, uma espécie de trava estrutural aos pequenos produtores. Como consequência, gerou-se uma quase impossibilidade de obter rendas agrícolas mínimas, na comparação com o salário mínimo. Some-se a isso a diminuição do desemprego e o aumento acima da inflação do salário mínimo há mais de década, além dos concomitantes processos de violência simbólica ${ }^{3}$, e podemos compreender porque se mantém vivo o êxodo rural.

A experiência da reforma agrária brasileira, na qual se conta com quase um quarto de toda a chamada agricultura familiar, é elucidativa: baixa produção e alta rotatividade (MELLO, 2006; MELLO, 2014; MELLO; BISPO, 2012). Não seria muito otimismo achar que, com as mais arriscadas e menos produtivas práticas "agroecológicas", o quadro mudaria?

Dito isso, gostaríamos de propor um caminho analítico ${ }^{4}$ que dê conta de compreen-

\footnotetext{
${ }^{3}$ Mais do que se dar conta dos salários melhores da cidade, fruto da unificação do mercado de trabalho, Bourdieu (2000), estudando camponeses franceses na década de 1970, acrescenta à análise a unificação dos mercados de bens simbólicos (a exemplo do matrimonial), nos quais as categorias de percepção são abaladas e se rompe com uma espécie de localocentrismo, expondo os camponeses a um mundo onde são vistos e passam a ser ver como inferiores, acelerando a fuga. Sendo ela, especialmente, feminina, o celibato masculino se tornava, então, um fenômeno importante.

4 Outra possibilidade seria pela via da sociologia do consumo, valendo-se do mesmo aporte teórico.
} 
der como tornou possível o ingresso da "agroecologia" nas políticas públicas brasileiras. Sugerimos como ponto de partida a proposição de Bourdieu (2007), quando estudou a sociedade francesa da década de 1970, a respeito das práticas sociais distintivas que expressam as condutas de classe no Estado contemporâneo.

A construção teórica de um campo de forças, no sentido de Bourdieu, como propõe Navarro - ainda que devamos considerar os limites do conceito para a situação brasileira, conforme Coradini (1996), seria produtiva. Mas, para tal - e retomando a nota de rodapé 12 do texto analisado -, talvez fosse o caso de incluir o conceito de habitus, essa espécie de adaptação subjetiva à objetividade do mundo, sem o qual, como bem alerta Navarro, não caberia o conceito de campo. Na medida em que o habitus se expressa em práticas culturais e visão de mundo, temos a oportunidade de avaliar subgrupos sociais, melhor dizendo, frações de classe (ou mesmo frações geracionais), suas práticas e estratégias numa determinada situação histórica.

Uma dimensão de análise possível é avaliar o encontro de habitus predispostos a uma proposição de mundo, um "encaixe" específico que dá sentido às condutas e proporciona lucros simbólicos aos agentes. Estudamos isso brevemente no Incra, em que aquele mesmo discurso político-ideológico era reproduzido ou pelo menos subjazia à prática burocrática e que resultou na expulsão, num determinado assentamento, de grupos adversários ao que seria o "núcleo militante agroecológico" e na canalização dos recursos públicos para este (MELLO, 2010).

Ali, e talvez não só ali, outros elementos entraram em jogo para tornar possível a conformação encontrada, indicando outra possibilidade de análise, de certa forma, insinuada por Navarro quando fala de intimidação partidária na Embrapa. Diz respeito a uma razoável sobrevivência de relação, digamos, arcaicas, no Estado brasileiro que podem resultar num elevado grau de heteronomia da instituição, por exemplo (mas não se resumindo a isso), fruto de relações patrão-cliente.

Navarro categorizou três subgrupos dentre os "agroecologistas": o "núcleo político" (grupo dominante e manipulador), o "núcleo operacional" e o "núcleo de militantes", ambos ingenuamente dominados pelos primeiros. A construção sociológica de um ponto de vista dos pontos de vista dos agentes num campo estruturado poderá permitir que não se encerre a questão apenas nesta denúncia de manipulação, ainda que não se negue tal fato. $\mathrm{O}$ estudo de trajetória dos agentes envolvidos ajudaria a caracterizar os habitus propensos a determinadas estratégias discursivas e práticas.

No entanto, que habitus seria esse que tornaria possível não uma conformação de um campo propriamente, mas, pelo menos, uma maior inteligibilidade da problemática? Uma pista poderia ser o estudo de grupos contraculturais ${ }^{5}$, sendo os agentes que transitam em torno dos subgrupos citados um recorte empírico inicial possível. Bourdieu

\footnotetext{
${ }^{5}$ Há um amplo debate sobre a expressão. Citem-se alguns elementos levantados pela literatura: ampliação do acesso à areligiões do self (STEIL; CARVALHO, 2008), Hare Krishna (GUERRIERO, 2009), subculturas juvenis, tais como hippies (RESENDE; VIEIRA, 1992), repúdio à tecnocracia da sociedade industrial (confundido, por vezes, com ocidental), antiintelectualismo, crise de confiança nas instituições, escapismo pequeno-burguês, narcisismo, anarquismo, orientalismo etc. Seja qual for o enfoque, trata-se de um desajuste à cultura hegemônica, não implicando necessariamente numa ideologia específica (CAPELLARI, 2007).
} 
(2007) descreveu como uma fração específica, chamada por ele de nova pequena burguesia, estabelecia práticas distintivas que, apesar de espelhadas na nova burguesia, procuravam denegar as hierarquias sociais, estabelecendo uma nova, ainda que com as velhas armas, como o moralismo. Fala de um

[....] proselitismo ético desses profetas éticos das sociedades burocráticas assume, naturalmente, o oposto da moral ascética da pequena burguesia estabelecida. [...] suas tomadas de posição éticas e políticas tem como princípio a rejeição de tudo o que, neles mesmos, existe como finito, definido, definitivo, em resumo, pequeno-burguês, ou seja, a recusa de 'serem arrumados' em determinado lugar do espaço social, utopismo prático que, até então, era o privilégio dos intelectuais e que os predispõe a acolher todas as formas de utopia (BOURDIEU, 2007, p. 347).

A seguir, o autor, desvelando a tentativa de inclassificabilidade do grupo em questão, apresenta um longo index do que chamou de anticultura adolescente, que, sintomaticamente, inicia com "agricultura biológica" (a corrente de agricultura ecológica mais forte na França, à época) e passa por anticientismo. São expressões "mal disfarçadas por uma espécie de sonho de vôo social e por um esforço desesperado para arrancar-se da força de atração do campo social de gravidade" (BOURDIEU, 2007, p. 348). Por fim, guiados por seu humor antiinstitucional e pela preocupação de escapar a tudo o que pode lembrar as competições, hierarquias e classificações, e, acima de tudo, classificações escolares, saberes hierarquizados e hierarquizantes, abstrações teóricas ou competências técnicas, os novos intelectuais inventam uma arte de viver que lhes garante, pelo menor custo, as gratificações e o prestígio do intelectual [...] (BOURDIEU, 2007, p. 349).

Essa fuga romântica do mundo social também se passaria via enaltecimento da natureza ${ }^{6}$ e conformaria parte de uma estratégia de revolta na forma de um conservadorismo iluminado.

Em suma, há pelos menos duas dimensões de análise que podem ajudar a entender como o discurso da "agroecologia" penetra na política pública: as fissuras de um Estado ainda animado por processos clientelísticos e a adesão dóxica de grupos contraculturais. São hipóteses a serem trabalhadas por meio de uma averiguação etnográfica, interrogando sobre as trajetórias dos agentes, a fim de compreender suas estratégias e as questões que os motivam.

\section{REFERÊNCIAS}

ALVES, E.; ROCHA, D. P. Ganhar tempo é possível? In: GASQUES, J. G.; VIEIRA FILHO, J. E. R.; NAVARRO, Z. A agricultura brasileira: desempenho recente, desafios e perspectivas. Brasília: IPEA/ MAPA, 2010. p. 275-290.

\footnotetext{
${ }^{6}$ Nessa esteira, os camponeses tenderiam a ser enquadrados como guardiões de uma natureza transformada em paisagem aos citadinos (BOURDIEU, 1977).
} 
BOURDIEU, P. Une classe objet. Actes de la recherche em sciences sociales, Paris, n. 1, v. 17, p. 2-5, 1977.

. A ontologia política de Martin Heidegger. Campinas: Papirus, 1989.

Reprodução proibida: a dimensão simbólica da dominação econômica. In: BOURDIEU, P. O campo econômico: a dimensão simbólica da dominação. São Paulo: Papirus, 2000. p. 93-119.

. A distinção: crítica social do julgamento. São Paulo: Edusp, 2007.

CAPELLARI, M. A. O Discurso da contracultura no Brasil: o underground através de Luiz Carlos Maciel (c. 1970). Tese (Doutorado em História Social) - Faculdade de Filosofia, Letras e Ciências Humanas, Universidade de São Paulo, 2007.

CORADINI, O. L. O referencial teórico de Bourdieu e as condições para sua aprendizagem e utilização. Veritas, Porto Alegre, v. 41, n. 162, p. 207-220, jun. 1996.

GUERRIERO, S. Caminhos e descaminhos da contracultura no Brasil: o caso do Movimento Hare Krishna. Nures, São Paulo, n. 12, 2009.

MELLO, P. F. Evasão e rotatividade em assentamentos rurais no Rio Grande do Sul. Dissertação (Mestrado em Desenvolvimento Rural) - Faculdade de Ciências Econômicas, Universidade Federal do Rio Grande do Sul, 2006.

Sistemas de produção nos assentamentos rurais do Rio Grande do Sul, safra 2004-2005. Perspectiva Econômica, São Leopoldo, v. 9, n. 2, 2014. No prelo.

Clientelismo e brokerage na reforma agrária: a ascensão das novas elites. Tese (Doutorado em Desenvolvimento Rural) - Faculdade de Ciências Econômicas, Universidade Federal do Rio Grande do Sul, 2010.

MELLO, P. F.; BISPO. L. D. Compreendendo os assentamentos da Bahia. In: Congresso Brasileiro de Adminstração, Economia e Sociologia Rural - Nordeste, 7., 2012, Ilhéus. Anais... Ilhéus: UESC. Não paginado.

MENDRAS, H. Sociedades camponesas. Rio de Janeiro: Zahar, 1978.

NAVARRO, Z. Agroecologia: as coisas em seu lugar (a Agronomia brasileira visita a terra dos duendes) Colóquio - Revista do Desenvolvimento Regional - Faccat, Taquara, v. 10, n. 1, jan./jun. 2013

RESENDE, J.; VIEIRA, M. M. Subculturas juvenis nas sociedades modernas: os Hippies e os Yuppies. Revista Crítica de Ciências Sociais, Lisboa, n. 35, 1992.

STEIL, C. A.; CARVALHO, I. C. M. A sacralização da natureza e a 'naturalização' do sagrado: aportes teóricos para a compreensão dos entrecruzamentos entre saúde, ecologia e espiritualidade. Ambiente \& Sociedade, Campinas, v. 11, n. 2, p. 289-305, 2008. 